\title{
An approach using ddRADseq and machine learning for understanding geographic and bathymetric patterns of speciation in Antarctic gastropods (Mollusca)
}

\author{
Juan Moles ${ }^{1}$, Shahan Derkarabetian ${ }^{2}$, Stefano Schiaparelli ${ }^{3}$, Michael Schrödl ${ }^{4}$, Jesús \\ Troncoso $^{5}$, Nerida Wilson ${ }^{6}$, and Gonzalo Giribet ${ }^{2}$ \\ ${ }^{1}$ Harvard University Faculty of Arts and Sciences \\ ${ }^{2}$ Harvard University \\ ${ }^{3}$ University of Genova \\ ${ }^{4}$ Zoologische Staatssammlung München \\ ${ }^{5}$ Universidade de Vigo \\ ${ }^{6}$ The Australian Museum
}

April 28, 2020

\begin{abstract}
Sampling impediments and paucity of suitable material for molecular analyses have precluded the study of speciation and radiation of deep-sea species in Antarctic ecosystems. This knowledge may serve to establish the framework for evaluating future anthropogenic alterations, particularly in a highly susceptible region like Antarctica. Here, we analyze genome-wide single nucleotide polymorphisms (SNPs) obtained from double digestion restriction site-associated DNA sequencing (ddRADseq) for most species in the family Antarctophilinidae and throughout the geographic distribution and bathymetric ranges of these marine snails. We also reevaluate the fossil record associated with this taxon. In light of the new data provided we discuss relevant diversification processes and biogeographic and bathymetric affinities. Novel approaches in finding genetic distinctive lineages, including unsupervised machine learning variational autoencoder (VAE) plots, are further used to establish species hypothesis frameworks aided by available morphological data. In this sense, two new species and a complex of cryptic species are here identified, suggesting allopatric speciation connected to geographic or bathymetric isolation. We further, observe that the shallow waters around the Scotia Arc and on the continental shelf in the Weddell Sea present high endemism and diversity. In contrast, likely due to the glacial pressure during the Cenozoic, a deep-sea group with fewer species emerged expanding over great areas in the South-Atlantic Antarctic Ridge. Our study exemplifies how diachronic paleoclimatic and current environmental factors shaped Antarctic communities both at the shallow and deep-sea levels, promoting Antarctica as the center of origin for numerous taxa such as gastropod mollusks.
\end{abstract}

\section{Hosted file}

An approach using ddRADseq and machine learning for understanding geographic and bathymetric patterns o. available at https : //authorea . com/users/307837/articles/438789-an-approach-using-ddradseq-andmachine-learning-for-understanding-geographic-and-bathymetric-patterns-of-speciation-in-antarcticgastropods-mollusca 

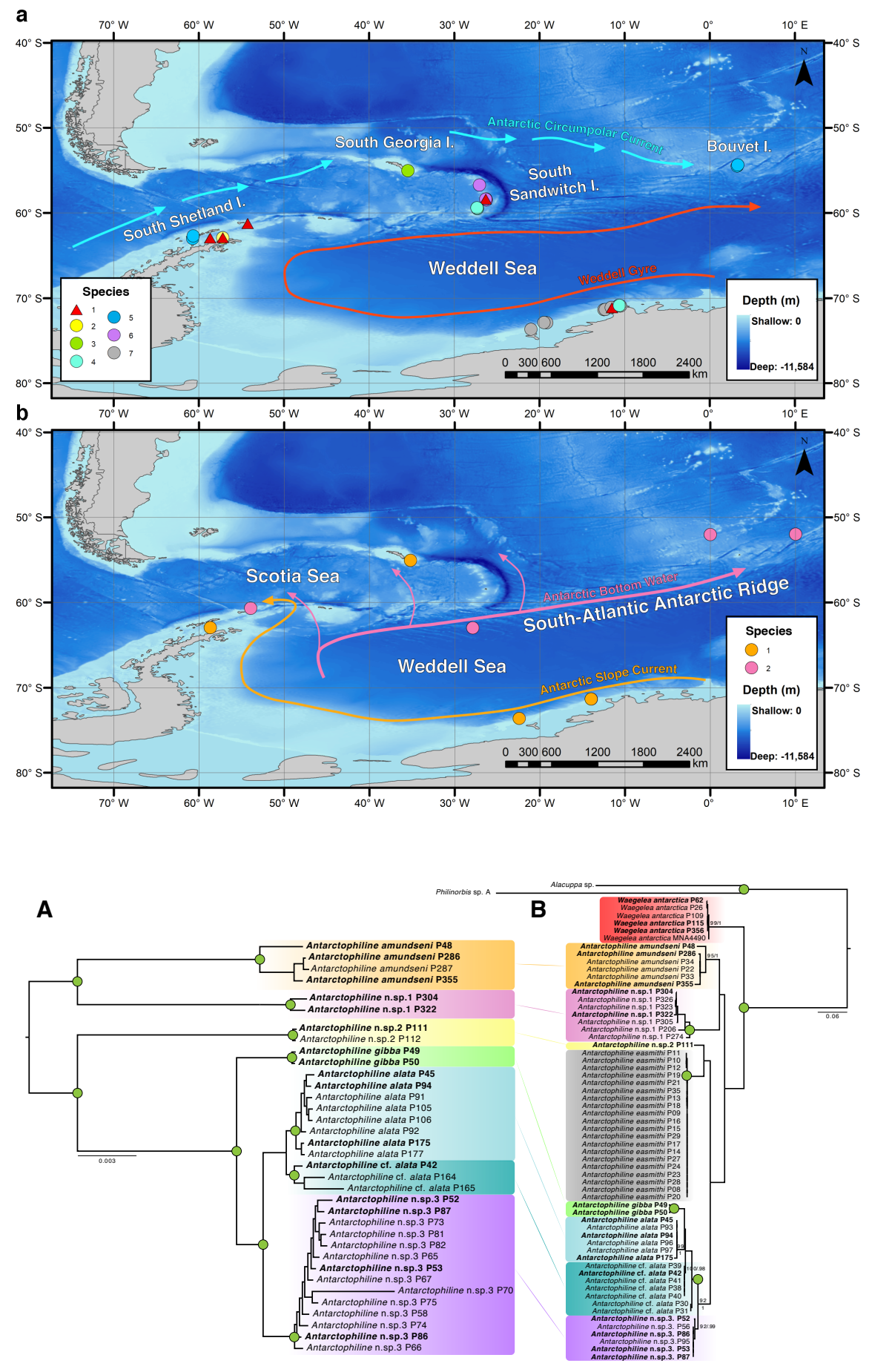


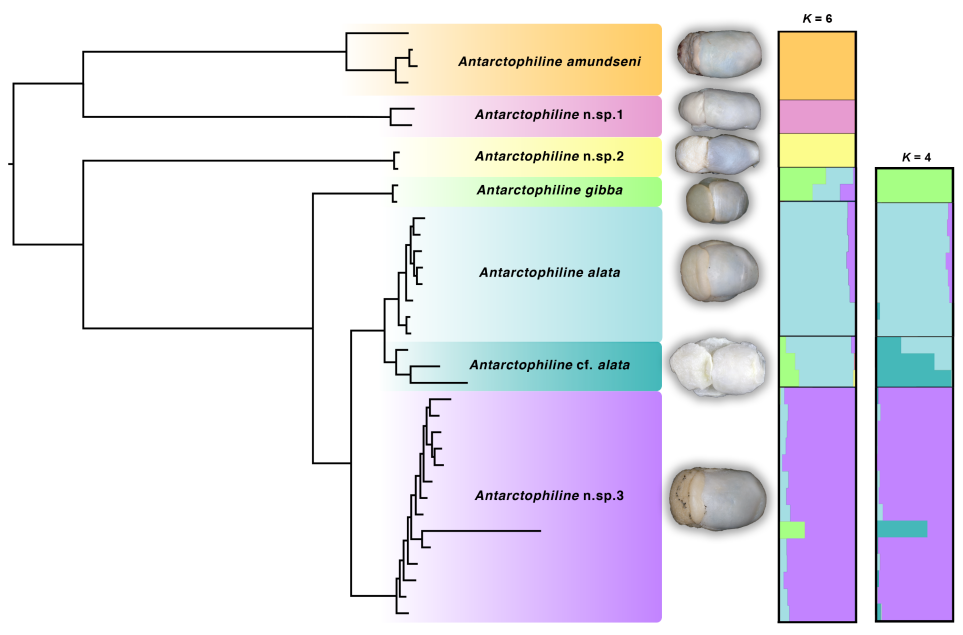

A

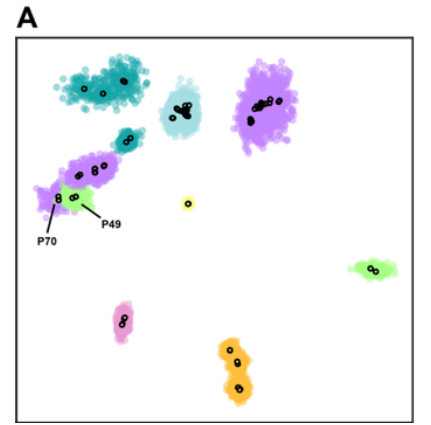

B

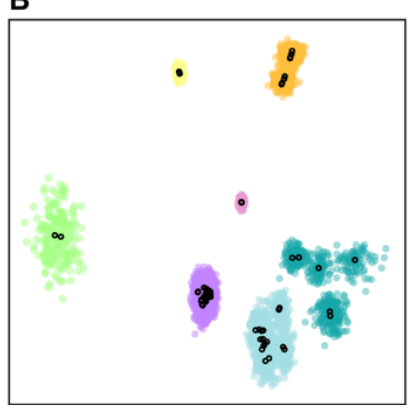

C

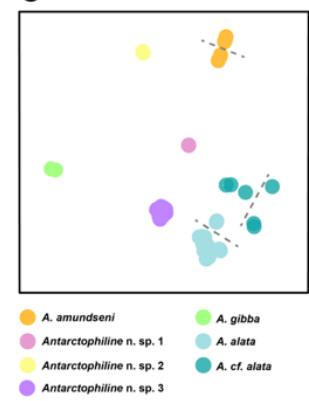

\section{Hosted file}

Figure 5.pdf available at https://authorea.com/users/307837/articles/438789-an-approach-usingddradseq-and-machine-learning-for-understanding-geographic-and-bathymetric-patterns-of-speciationin-antarctic-gastropods-mollusca

\section{Hosted file}

Supplementary_Table_S1.xlsx available at https://authorea.com/users/307837/articles/438789-anapproach-using-ddradseq-and-machine-learning-for-understanding-geographic-and-bathymetricpatterns-of-speciation-in-antarctic-gastropods-mollusca 


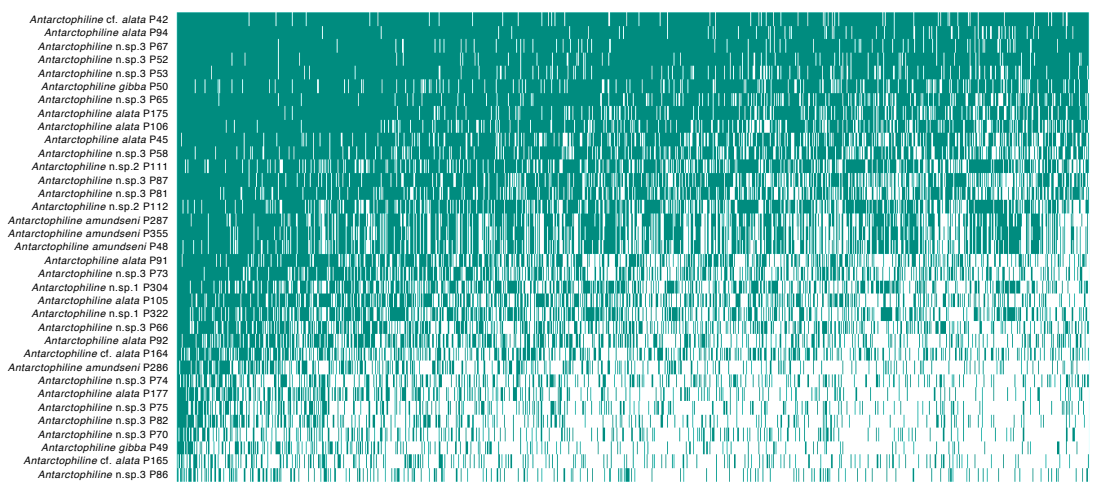

